\title{
Ô nhiễm rác thải sinh hoạt nông thôn Việt Nam: Thục trạng, nguyên nhân và giải pháp
}

\author{
Đỗ Thùy Trang, Ngô Thị Ngọc Bích
}

Hà Nội, ngày 6 tháng 12 năm 2021

Preprint DOI:

Gia tăng dân số, phát triển đô thị hóa nông thôn, thay đổi lối sống, tiêu dùng cá nhân tăng đã làm gia tăng về khối lượng rác thải sinh hoạt và hậu quả nặng nề là sự ô nhiễm rác thải sinh hoạt nông thôn [1]. Đối với một quốc gia đang phát triển như Việt Nam, vấn đề rác thải sinh hoạt nông thôn thực sự là nút thắt cần được gỡ bỏ.

Cùng với quá trình đô thị hóa nông thôn, người dân ngày càng có xu hướng di cư đến khu vực nông thôn định cư. Thực tế, Việt Nam có khoảng hơn 60 triệu dân sống ở vùng nông thôn, chiếm hơn $73 \%$ dân số cả nước. Dân cư tăng lên dẫn đến nhiều vấn đề về rác thải sinh hoạt và xử lý rác thải sinh hoạt. Theo báo Công thương, trung bình mỗi năm ở khu vực nông thôn phát sinh trên 13 triệu tấn rác thải sinh hoạt, nhưng tỷ lệ thu gom chỉ đạt $40 \%$, tỷ lệ tái chế chưa đạt đến $4 \%$, còn những rác thải chưa được xử lý thì xả trực tiếp ra môi trường [2]. Bên cạnh đó, các biện pháp về xử lý rác thải tại gia, tại địa phương chưa được quy hoạch rõ ràng, gây ra tình trạng tất cả các loại rác đều đổ chung một chỗ, ảnh hưởng đến công tác xử lý. Vì vậy, công tác thu gom, xử lý rác thải sinh hoạt ở khu vực nông thôn cần được nâng cao cải thiện.

Sự ô nhiễm rác thải sinh hoạt tại từng vùng nông thôn Việt Nam bị tác động bởi một vài yếu tố trọng điểm $[1,3]$ bao gồm nhiều yếu tố như yếu tố kinh tế, nhận thức con người, hệ thống quản lý và xử lý rác thải sinh hoạt, và sự thiếu quan tâm của các cấp chính quyền

Trước hết là yếu tố kinh tế, vấn đề đô thị hóa nông thôn, xây dựng nông thôn mới hiện đang là mục tiêu mà hầu hết các địa phương tại Việt Nam hướng tới, kéo theo sự thay đổi cơ cấu kinh tế, hình thức sản xuất kinh doanh và sự tập trung mạnh mẽ của các khu công nghiệp mới. Tuy nhiên, song song với đó là sự tăng lên về khối lượng của rác thải sinh hoạt nông thôn. 
Nhận thức con người, yếu tố này tồn tại thông qua suy nghĩ chủ quan về tác động của các loại rác thải khó phân hủy và hành động thực tế là sự không phân loại rác thải hay hành động vứt rác bừa bãi tại các điểm tập kết rác tự phát, vứt rác bừa bãi ra kênh ngòi, ao, rạch...

Hệ thống quản lý và xử lý rác thải sinh hoạt. Trên thực tế, tại nông thôn Việt Nam vẫn còn tồn tại phương thức quản lý rác thải thiếu quy hoạch thông qua hàng loạt bãi tập kết rác tự phát, hoạt động phân loại tại nguồn chưa được đẩy mạnh và phương thức xử lý rác thải chủ yếu là chôn lấp với kỹ thuật đơn giản [4].

Sự thiếu quan tâm của các cấp chính quyền. Thực tế cho thấy bộ máy chính quyền trong công tác quản lý, xử lý rác thải tại mỗi địa phương chưa được đồng bộ [5]. Bên cạnh đó, điều kiện vật chất và cam kết trong công tác thực hiện đẩy lùi ô nhiễm rác thải sinh hoạt còn trở ngại và chậm trễ. Nguồn nhân lực ít và yếu kém càng làm cho vấn đề thêm trầm trọng hơn.

Vấn đề ô nhiễm rác thải sinh hoạt nông thôn đã tác động đến môi trường sống và cuộc sống của con người [6]. Với số lượng rác thải tăng lên theo cấp số nhân, môi trường đất, nước, không khí tại nông thôn đều đang trong mức báo động. Điều này đã tác động trực tiếp đến đời sống sinh hoạt của con người khi chất lượng nguồn nước, không khí không được đảm bảo. Bên cạnh đó, việc sống trong một mùi hôi thối của rác, một bầu không khí đầy khói bụi còn gia tăng sự khó chịu và là một trong những tác nhân cho việc xuất hiện các bệnh lý về phổi, đường hô hấp, các bệnh về ruột...

Do vấn đề ô nhiễm rác thải sinh hoạt nông thôn luôn ngày càng trầm trọng, Nhà nước và các nhà chức trách tại các địa phương đã có những biện pháp để giải quyết như khuyến khích người dân sử dụng rác thải hữu cơ làm phân bón, phân chia rác hữu cơ, rác tái chế tại gia để dễ dàng cho công tác xử lý... Tuy nhiên, kết quả xử lý ô nhiễm rác thải sinh hoạt nông thôn vẫn còn khá hạn chế.

Để đi tìm lời giải căn cơ cho vấn đề ô nhiễm môi trường nói chung và rác thải nông thôn nói riêng, giáo sư Vương Quân Hoàng và các cộng sự của ông đã nghiên cứu và phát triển các lý thuyết về văn hóa môi trường (văn hóa hướng thượng). Các tác giả đã chỉ ra rằng, để giải quyết bài toán môi trường một cách bền vững, giá trị môi trường phải được tính vào các chi phí và lợi ích của các dự án hoặc kinh doanh [7]. Từ cách tiếp cận này, ông chỉ ra rằng doanh nghiệp, giáo dục [8] và khoa học chân chính [9] sẽ là yếu tố/nhân tố giúp nâng cao nhận thức môi trường [10] và giải quyết hiệu quả vấn đề môi trường trong tương lai.

Tóm lại, môi trường nông thôn ngày càng trở nên ô nhiễm ảnh hưởng đến sức khỏe của người dân và mỹ quan nông thôn. Bên cạnh các yếu tố khách quan như yếu tố kinh tế, sự hạn chế của người dân về môi trường, những nỗ lực và hành động thiếu hiệu quả của chính quyền là nguyên nhân góp phần làm cho tình trạng ô nhiễm nông thôn ngày càng trở nên trầm trọng. 
Văn hóa hướng thượng [11] được xây dựng/hình thành từ các tư tưởng văn hóa môi trường có thể là chìa khóa (lời giải) căn cơ cho vấn đề này. Xây dựng văn hóa môi trường (văn hóa hướng thượng) là quan trọng và cần thiết giúp nâng cao nhận thức về môi trường của người dân để từ đó chính họ sẽ tham gia hiệu quả trong việc xử lý ô nhiễm môi trường nông thôn trong thời gian tới.

Notes: Đây là bản thảo chưa hoàn chỉnh và chúng tôi tiếp tục cập nhật/hoàn thiện trong nhũng ngày (thời gian) tới.

\section{Tài liệu tham khảo}

[1] Astane ARD, Hajilo M. Factors affecting the rural domestic waste generation. Glob J Environ Sci Manag 2017;3:417-26. https://doi.org/10.22034/gjesm.2017.03.04.007.

[2] Uyen NM. Rác thải nông thôn - bài toán khó cần lời giải cụ thể. NguoiduatinVn 2021. https://www.nguoiduatin.vn/rac-thai-nong-thon-bai-toan-kho-can-loi-giai-cu-thea535233.html (accessed December 6, 2021).

[3] Han Z, Liu Y, Zhong M, Shi G, Li Q, Zeng D, et al. Influencing factors of domestic waste characteristics in rural areas of developing countries. Waste Manag 2018;72:4554. https://doi.org/10.1016/j.wasman.2017.11.039.

[4] Dung PD. Thực trạng rác thải sinh hoạt tại Việt Nam. VietEnvi 2017. https://congtyxulynuoc.com/thuc-trang-rac-thai-sinh-hoat-tai-viet-nam/ (accessed December 7, 2021).

[5] Nguyên nhân của các tồn tại trong công tác bảo vệ môi trường. Tổng Cục Môi Trường 2020.

[6] Thị Minh Hạnh PTT. Báo cáo môi trường quốc gia 2014- Chương 4 Tác động của ô nhiễm môi trường nông thô. 2014.

[7] Vuong QH. The semiconducting principle of monetary and environmental values exchange. Econ Bus Lett 2021;10:284-90. https://doi.org/10.17811/ebl.10.3.2021.284290.

[8] Vuong Q. From children's literature to sustainability science, and young scientists for a more sustainable Earth From children's literature to sustainability science, and young scientists for a more sustainable Earth 2020;24:2019-21.

[9] Vuong Q-H. Western monopoly of climate science is creating an eco-deficit culture. Econ L Clim Insight 2021:1-9.

[10] Vuong QH, Ho MT, Nguyen MH, Pham TH, Vuong TT, Khuc Q, et al. On the environment-destructive probabilistic trends: A perceptual and behavioral study on video game players. Technol Soc 2021;65:101530. https://doi.org/10.1016/j.techsoc.2021.101530.

[11] Khuc Q Van. Environmental culture thoughts to make a better world for our nature and children. OSF Prepr 2021;65:6. https://doi.org/10.31219/osf.io/g5zex. 